\title{
PENGARUH STRATEGI PROMOSI ASURANSI SYARIAH TERHADAP NASABAH ASURANSI JIWA AXA PADA BANK SYARIAH MANDIRI
}

\author{
Raja Sakti Putra Harahap \\ STAI Syekh H. Abdul Halim Hasan Al-Ishlahiyah Binjai \\ Putrasafat036@gmail.com \\ Sukmala Devi \\ STAI Syekh H. Abdul Halim Hasan Al-Ishlahiyah Binjai \\ Sukmalladevi021@gmail.com
}

\begin{abstract}
This study aims to determine the Influence of Sharia Insurance Promotion Strategy on Public Interest to Become AXA Life Insurance Customers at Bank Syariah Mandiri Binjai Branch. This study uses 2 variables consisting of variables $X$ (Islamic insurance promotion strategy) and $Y$ (public interest in becoming AXA life insurance customers). The research design used is quantitative research using simple linear regression analysis techniques with the help of SPSS version 18.0. The results of data processing show that the promotion strategy of sharia insurance is $45.1 \%$ while the remaining $54.9 \%$ is influenced by factors other than the promotion strategy of sharia insurance. If the sharia insurance promotion strategy is ignored, the public's interest in becoming AXA life insurance customers will remain at 5,955. Meanwhile, if the value of the sharia insurance promotion strategy variable increases by 1 , it will be followed by an increase in public interest in becoming AXA life insurance customers by 0.623 . The results of this study prove that t_hitung (3.389) > t_table (1.68), meaning that the sharia insurance promotion strategy has an effect on public interest in becoming AXA life insurance customers. The significance level is 0.0000 .05 , so it is known that the independent variable has a significant and positive effect on the dependent variable.
\end{abstract}

Keywords: Strategy, Promotion, Sharia Insurance

\begin{abstract}
Abstrak
Penelitian ini bertujuan untuk mengetahui Pengaruh Strategi Promosi Asuransi Syariah Terhadap Minat Masyarakat Untuk Menjadi Nasabah Asuransi Jiwa AXA Pada Bank Syariah Mandiri Cabang Binjai. Penelitian ini menggunakan 2 variabel yang terdiri dari variabel $\mathrm{X}$ (strategi promosi asuransi syariah) dan Y (minat masyarakat untuk menjadi nasabah asuransi jiwa AXA). Desain penelitian yang digunakan yaitu penelitian kuantitatif dengan menggunakan teknik analisis regresi linier sederhana dengan bantuan SPSS versi 18.0. Hasil dari pengolahan data menunjukkan bahwa strategi promosi asuransi syariah sebesar $45,1 \%$ sedangkan sisanya 54,9\% dipengaruhi oleh faktor lain selain strategi promosi asuransi syariah. Jika strategi promosi asuransi syariah diabaikan maka minat masyarakat untuk menjadi nasabah asuransi jiwa AXA akan tetap sbesar 5,955. Sedangkan jika nilai variabel strategi promosi asuransi syariah meningkat sebesar 1, maka akan diikuti oleh peningkatan minat masyarakat untuk menjadi nasabah asuransi jiwa AXA sebesar 0,623. Hasil penelitian ini terbukti bahwa t_hitung $(3,389)>t$ tabel $(1,68)$, berarti strategi promosi asuransi syariah berpengaruh minat masyarakat untuk menjadi nasabah asuransi jiwa AXA. Tingkat signifikasi yaitu 0,000 0,05, sehingga
\end{abstract}


diketahui bahwa variabel independen berpengaruh secara signifikan dan bersifat positif terhadap variabel dependen.

Kata kunci: Strategi, Promosi, Asuransi syariah.

\section{Pendahuluan}

Dalam produk asuransi, adanya promosi sangat berpengaruh dalam perkembangan asuransi tersebut. Dimana promosi menjadi sarana pemasaran dalam memasarkan produk asuransi maupun sebagai sarana untuk mengenalkan asuransi kepada masyarakat luas agar masyarakat tahu dan berminat untuk berasuransi. Adapun kegiatan yang termasuk dalam bentuk-bentuk promosi yang dapat dilakukan perusahaan asuransi dalam memasarkan produknya adalahperiklanan, personal selling, sales promotion, dan promosi penjualan. Periklanan (advertising) yaitu Bank Muamalat Indonesia dalam memasarkan produk asuransi jiwa (prudensial life insurance) melalui surat kabar, media online, pemasangan spanduk ditempat strategis, pamphlet, serta percetakan brosur baik disebarkan di setiap cabang atau pusat-pusat perbelanjaan. Penjualan pribadi atau (personal selling) yaitu personal selling dengan mengikuti berbagai launching, melakukan pendekatan kepada nasabah-nasabah yang pontensial berdasarkan pipeline yang dibuat oleh Bank Syariah Mandiri Cabang Binjai.Sales promotion yaitu cara promosi dengan cara peragaan, pertunjukan dan pameran, demonstrasi dan berbagai macam usaha penjualan yang bersifat rutin. Promosi penjualan, strategi pemasaran yang dilakukan olehBank Syariah Mandiri Cabang Binjai melalui kegiatan promosi penjualan yaitu dengan cara kegiatan membuka stan-stan di instansi pemerintahan Kota Binjai (open table), presentasi ke kantor-kantor, pemberian cideramata atau souvenir, hadiah, serta kenang-kenangan terhadap nasabah yang loyal. Adapun biaya promosi yang digunakan adalah sebagai berikut:

\begin{tabular}{|c|c|c|c|c|}
\hline \multicolumn{5}{|c|}{$\begin{array}{c}\text { Tabel 1 } \\
\text { Biaya PromosiAsuransi Jiwa AXABank Syariah } \\
\text { Periode 2016-2019 }\end{array}$} \\
\hline $\begin{array}{l}\text { Bulan/ } \\
\text { Tahun }\end{array}$ & \multicolumn{4}{|c|}{$\begin{array}{c}\text { Biaya Promosi (dalam } \\
\text { ribuan rupiah) }\end{array}$} \\
\hline & 2016 & 2017 & 2018 & 2019 \\
\hline Jan & 350 & 370 & 400 & 500 \\
\hline Feb & 390 & 400 & 450 & 460 \\
\hline Mar & 400 & 450 & 475 & 525 \\
\hline
\end{tabular}


60 AT-TAWASSUTH: Jurnal Ekonomi Islam, Volume VI No. 1

Januari - Juni 2021: 58 - 65

\begin{tabular}{|c|c|c|c|c|}
\hline April & 330 & 350 & 425 & 425 \\
\hline Mei & 325 & 330 & 375 & 400 \\
\hline Jun & 300 & 300 & 390 & 490 \\
\hline Jul & 360 & 460 & 430 & 540 \\
\hline Agust & 380 & 390 & 490 & 590 \\
\hline Sept & 410 & 350 & 380 & 550 \\
\hline Okt & 450 & 400 & 485 & 560 \\
\hline Nov & 425 & 500 & 525 & 500 \\
\hline Des & 430 & 475 & 500 & 600 \\
\hline Jumlah & 4550 & 4775 & 5325 & 6140 \\
\hline
\end{tabular}

Adapun fenomena yang terjadi adalah,asuransi syariah menyadari bahwa promosi menjadi hal yang penting untuk dilakukan agar masyarakat luas dapat mengetahui akan produk asuransi tersebut. Produk asuransisyariahdalam melakukan promosi dengan cara memasang iklan di internet, hal ini diharapkan mampu menarik minat calon nasabah untuk berasuransi di asuransi syaiah Bank Syariah Mandiri Cabang Binjai. Nasabah asuransi jiwa AXA pada Bank Syariah Mandiri Cabang Binjai pada tahun 2016 mencapai 708 nasabah, pada tahun 2017 mencapai 956 nasabah, pada tahun 2018 mencapai 1.138 nasabah, dan pada tahun 2019 mencapai 1.023 nasabah.

Walaupun promosi bukan satu-satunya cara untuk meningkatkan minat masyarakat untuk menjadi nasabah, tetapi cukup punya andil dalam mempengaruhi pencapaian target yang diinginkan. Untuk itu promosi harus dilaksanakan dengan cara serta media yang tepat dan sesuai sehingga promosi menjadi efektif dan diharapkandapat mencapai sasaran dalam upaya meningkatkan minat masyarakat untuk menjadi nasabahasuransi jiwa AXA. Tetapi masih saja sebagaian masyarakat tidak mengetahui apa ituasuransi jiwa AXA karena kurangnya promosi yang diberikan oleh pihak Bank Syariah Mandiri Cabang Binjai, selain dengan promosi juga harus dipertahankan demi loyalitas nasabahyang sudah ada, dengan begitumasyarakat akan tetap berminat untuk menjadi nasabah Bank Syariah Mandiri Cabang Binjai.

Bertitik tolak dari uraian di atas, maka penulis tertarik untuk mengkaji, meneliti serta membahas tentang seberapa besar dan sejauh mana strategi promosi 
yang dilakukan Bank Syariah Mandiri Cabang Binjai dalam menarik minat masyarakat untuk menjadi nasabah asuransi jiwa AXAdengan mengangkat judul "Pengaruh Strategi Promosi Asuransi Syariah Terhadap Nasabah Asuransi Jiwa AXA Di Bank Syariah Mandiri Cabang Binjai”.

\section{Landasan Teori}

\section{Asuransi Syariah}

Asuransi syariah merupakan cara atau metode untuk memelihara manusia dalam menghindari resiko (ancaman) bahaya yang beragam yang akan terjadi dalam hidupnya, dalam perjalanan kegiatan hidupnya atau dalam aktivitas ekonominya sesuai dengan syariat islam.

2. Strategi Pemasaran Promosi

Strategi adalah penetapan misi perusahaan, penetapan sasaran organisasi dengan meningkatkan kekuatan eksternal dan internal, perumusan kebijakan dan implementasinya secara tepat, sehingga tujuan dan sasaran utama organisasi akan tercapai.

Promosi adalah kegiatan mengkomunikasikan informasi dari penjual kepada konsumen atau nasabah dalam saluran penjualan barang dan jasa yang ada di perusahaan tersebut. Melalui periklanan suatu perusahaan mengarahkan komunikasi pada nasabah masyarakat melalui media-media yang disebut dengan media masa seperti koran, majalah, tabloid, radio, televisi dan direct mail.

Ada berbagai cara yang digunakan dalam melakukan promosi dan juga sebagai indikator dalam promosi yaitu diantaranya adalah periklanan, penjualan pribadi, sales promotion, dan promosi penjualan.

3. Minat Nasabah

Minat adalah perpaduan antara keinginan dan kemauan yang dapat berkembang. Minat juga dikatakan sebagai sumber motivasi yang mendorong orang untuk melakukan sesuatu yang mereka inginkan bila mereka bebas memilih.

Banyak hal yang dapat mempengaruhi minat, baik dari individu maupun lingkungan masyarakat adalah sebagai berikut:

a. Faktor dorongan, yang berasal dari dalam. Kebutuhan ini dapat berupa kebutuhan yang berhubungan dengan jasmani dan kejiwaan.

b. Faktor motif sosial. Timbulnya minat dari seseorang dapat didorong dari motif sosial yaitu kebutuhan untuk mendapatkan penghargaan dan lingkungan dimana mereka berada. 
c. Faktor emosional. Faktor ini merupakan ukuran intensitas seseorang dalam menaruh perhatian terhadap sesuatu kegiatan atau obyek tertentu.

\section{Metodologi Penelitian}

Penelitian ini merupakan penelitian analisis regresi sederhana dengan menggunakan metode penelitian kuantitatif. Populasi dalam penelitian ini adalah keseluruhan nasabah asuransi syariah di Bank Syariah Mandiri yang berjumlah 1.023nasabah.Jumlah sampel yang diambil adalah 43nasabah dengan teknik pengambilan sampel menggunakan rumus slovin. Variabel yang digunakan dalam penelitian ini adalah strategi promosi asuransi syariah (variabel $\mathrm{X}$ ) dan nasabah asuransi jiwa AXA (variabel Y). Metode pengumpulan data yang digunakan adalah dokumentasi dan angket.Sedangkan metode analisis data adalah deskriptif statistik dan statistik inferensial yang terdiri dari uji normalitas, uji keofesien determinasi majemuk $\left(\mathrm{R}^{2}\right)$, uji $\mathrm{t}$, dan uji regresi linear sederhana

\section{Hasil Dan Pembahasan Penelitian}

1. Uji Normalitas

Pada normalisasi data dengan p-plot, data yang digunakan akan dinyatakan berdistribusi normal. Hal tersebut terjadi karena titik-titik residual tersebut berasal dari data-data berdistribusi normal dan mengikuti garis diagonal atau garis linear. Dengan demikian, dapat disimpulkan bahwa regresi telah memenuhi normalitas.

2. Koefesien Determinasi Majemuk $\left(\mathrm{R}^{2)}\right.$

Hasil dari uji koefesien determinasi dapat dilihat bahwa nilai $\mathrm{R}=0,672$ (67,2\%) maka nilai-nilai koefisien determinasi () adalah $\mathrm{R} \times \mathrm{R}=$ sebesar 0,451 $(45,1 \%)$. Artinya bahwa variabel terikat nasabah asuransi jiwa AXA dipengaruhi oleh varabel bebas yakni strategi promosi asuransi syariah sebesar 45,1\% Sisanya $54,9 \%$ dipengaruhi oleh faktor lain selain strategi promosi asuransi syariah.

3. Uji t

Hasil dari uji $\mathrm{t}$ dapat diketahui bahwa dengan 43 sampel, nilai dilihat berdasarkan derajat bebas $=\mathrm{n}-\mathrm{k}$, maka $43-2=41$, dengan tingkat signifikan 0,05 maka adalah 1,68.

Hal ini juga dapat dibuat yang menjadi panduan untuk menerima dan menolak hipotesis, yang dapat disimpulkan bahwa $X=5,809$, yang menunjukkan bahwa $(5,809)(1,68)$. Hal ini memberikan kesimpulan bahwa diterima, yaitu strategi promosi asuransi syariah berpengaruh secara signifikan terhadap nasabah asuransi 
jiwa AXA. Sedangkan variabel strategi promosi asuransi syariah memiliki p-value 0,000 0,05, maka di tolak, atau strategi promosi asuransi syariah secara signifikan berpengaruh terhadap nasabah asuransi jiwa AXA pada Bank Syariah Mandiri Cabang Binjai.

Dengan demikian strategi promosi asuransi syariah berpengaruh secara signifikan terhadap nasabah asuransi jiwa AXA pada Bank Syariah Mandiri Cabang Binjai.

4. Uji Regresi Linear Sederhana

Hasil uji regresi linear sederhana dapat dilihat:

$$
\mathrm{Y}=5,955+0,623 \mathrm{X}
$$

Arti dari persamaan regresi linear sederhana yang diperoleh di atas adalah sebagai berikut:

1) Nilai konstanta sebesar 5,955 , artinya jika strategi promosi asuransi syariah di abaikan maka minat masyarakat untuk menjadi nasabah asuransi jiwa AXA akan tetap sebesar 5,955.

2) Koefisien regresi variabel strategi promosi asuransi syariah sebesar 0,623, artinya jika nilai variabel strategi promosi asuransi syariah meningkat sebesar 1, maka akan diikuti oleh minat masyarakat untuk menjadi nasabah asuransi jiwa AXA masyarakat sebesar 0,623. Angka-angka tersebut di atas menunjukkan bahwa variabel strategi promosi asuransi syariah berpengaruh ke arah positif dan searah terhadap minat masyarakat untuk menjadi nasabah asuransi jiwa AXA.

\section{Kesimpulan}

Dari hasil penelitian yang dilakukan penulis, maka dapat ditarik kesimpulan bahwa strategi promosi asuransi syariah berpengaruh secara reaktif dan signifikan terhadap nasabah asuransi jiwa AXA pada Bank Syariah Mandiri Cabang Binjai. Saran

Berdasarkan dari penelitian yang dilakukan penulis, diharapkan pada pihak PT. Bank Syariah Mandiri KCP. Binjai agar terus meningkatkan strategi promosi asuransi syariah serta terus menerus memperbaiki sistem promosi asuransi syariah yang diterapkan. Karena faktor strategi promosi asuransi syariah telah terbukti berpengaruh terhadap minat masyarakat untuk menjadi nasabah asuransi jiwa AXA. Dengan asumsi semakin baik strategi promosi asuransi syariah yang di terapkan, maka akan semakin tinggi minat masyarakat untuk menjadi nasabah 
64 AT-TAWASSUTH: Jurnal Ekonomi Islam, Volume VI No. 1

Januari - Juni 2021: 58 - 65

asuransi jiwa AXA. Dari hasil penelitian telah terbukti bahwa strategi promosi asuransi syariah berpengaruh positif dan searah terhadap minat masyarakat untuk menjadi nasabah asuransi jiwa AXA pada PT. Bank Syariah Mandiri KCP. Binjai. Dengan demikian masyarakat akan lebih berminat serta semakin bertambah jumlahnya untuk terus menjadi nasabah asuransi jiwa AXA pada PT. Bank Syariah Mandiri KCP. Binjai.

\section{Daftar Pustaka}

Departemen Agama RI, Alqur' an dan Terjemahnya, Jakarta, PT. Karya Toha Putera Semarang, 2014.

Ali, Hasan, Asuransi Dalam Perspektif Hukum Islam, Jakarta: Kencana, 2004.

Anogara, Panji, Pengantar Bisnis (Pengelolaan Bisnis dalam Era Globalisasi), Rineka Cipta: Jakarta.

PT. Bank Syariah Mandiri, Sejarah Perusahaan, di akses pada tanggal 24 September 2020 pukul 09.39 di https://www.mandirisyariah.co.id/tentang-kami/sejarah.

PT. Bank Syariah Mandiri, Visi dan Misi Perusahaan, di akses pada tanggal 24 $\begin{array}{llll}\text { September } & 2020 & \text { pukul } & 09.48\end{array}$ https://www.mandirisyariah.co.id/tentangkami/visi-misi.

PT. Bank Syariah Mandiri, Budaya Perusahaan, di akses pada tanggal 24 September 2020 pukul 09.52 di https://www.mandirisyariah.co.id/tentangkami/budayaperusahaan.

PT. Bank Syariah Mandiri, Dewan Pengawas Syariah, di akses pada tanggal 24 $\begin{array}{llll}\text { September } & 2020 & \text { pukul } & 10.07\end{array}$ https://www.mandirisyariah.co.id/tentangkami/dewan-pengawas-syariah.

PT. Bank Syariah Mandiri, Struktur Organisasi Perusahaan, di akses pada tanggal 24 September 2020 pukul 10.09 dari https://www.mandirisyariah.co.id/tentangkami/struktur-organisasi

Fandy, Strategi Pemasaran. Edisi ke 3,Yogyakarta: Undang-Undang dasar 1945, 2008.

Ghozali, Imam, Aplikasi Analisis Multivariate dengan program SPSS, Universitas Diponegoro, 2013.

Gitosudarmo, Indriyo, Pengantar Bisnis, Yogyakarta: BPFE, 2003.

Iskandarwasid \& Dadang Sunendar, Strategi Pembelajaran Bahasa, Bandung: Rosda, Cet. Ke-3, 2011.

http://digilib.uinsby.ac.id/349/5/Bab\%202.pdf pada tanggal 23 April 2020 pukul 11.45 WIB. 
http://eprints.walisongo.ac.id/7278/3/BAB\%20II.pdf pada tanggal 23 April 2020 pukul 11.00 WIB.

http://etheses.uin-malang.ac.id/2612/6/05410051_Bab_2.pdf pada tanggal 23 April 2020 pukul 11.20 WIB.

http://etheses.uinmataram.ac.id/231/1/Kurniati152135210.pdf pada tanggal 23 April 2020 pukul 09.00 WIB.

https://eprints.uny.ac.id/7795/3/bab\%202\%20- 05503241026.pdf pada tanggal 23 April 2020 pukul 12.00 WIB.

Kasmir, Kewirausahaan - Edisi Revisi, Jakarta: PT Raja Grafindo Persada, 2013.

Kuncoro, Mudrajat, Metode Riset Untuk Bisnis dan Ekonomi Edisi 3, 2011. Muhammad, Metodologi Penelitian Ekonomi Islam: Pendekatan Kuantitatif, Jakarta: Raja Grafindo, 2008.

Novitasari, Pengaruh Promosi dan Kualitas Layanan terhadap Minat Nasabah dalam memilih PT. Asuransi Takaful Keluarga Palembang, 2017.

Nur Rianto, Al Arif, Pemasaran Strategik Pada Asuransi Syariah, Bekasi: Gramata Publising, 2015.

Rasyid, Sudrajat, dkk, Kewirausahaan Santri (Bimbingan Santri mandiri), Jakarta Timur: PT. Citra Yudha Alamanda Perdana, 2005.

Sari, Darmayanto, Kuliah Manajemen Pemasaran, Bandung: PT. Sarana Tutorial Nurani Sejahtera, 2011.

Sedarmayanti, dkk., Metodologi Penelitian, Bandung: Mandar Maju, 2011.

Stainer George, dan John Minner, Manajemen Stratejik, Jakarta: Erlangga, tt. Suharno dan Yudi Sutarso, Marketing in Practice, Yogyakarta: Graha Ilmu, 2010.

Suhendi, Hendi, Fiqh Muamalah, Jakarta: Raja Grafindo Persada, 2005.

Sukurin, Pokok-pokok Psikologis Pendidikan, Yogyakarta: FIP-IKIP, 2003.

Sula, Muhammad Syakir, Asuransi Syariah, Jakarta: Gema Insani, 2004.

Suliyanto, Ekonometrika Terapan: Teori \& Aplikasi dengan SPSS, Yogyakarta: ANDI OFFSET, 2011.

Syahrum dan Salim, Metodologi penelitian kuantitatif, Bandung: Cita pustaka Media, 2012.

Tantiya, Absyarina, Pengaruh Premi, Promosi, dan Kualitas Pelayanan terhadap Minat Masyarakat Menjadi Nasabah pada PT. Asuransi Takaful Keluarga Cabang Banda Aceh, 2019. 